\title{
Young Fruit and Auxin Transport Inhibitors Affect the Response of Mature 'Valencia' Oranges to Abscission Materials via Changing Endogenous Plant Hormones
}

\author{
Rongcai Yuan, Walter J. Kender, and Jacqueline K. Burns ${ }^{1}$ \\ University of Florida, Institute for Food and Agricultural Sciences, Citrus Research and Education \\ Center, 700 Experiment Station Road, Lake Alfred, FL 33850-2299
}

\begin{abstract}
AdDitional INDEX words. Citrus sinensis, abscission, abscisic acid, 5-chloro-3-methyl-4-nitro-1 H-pyrazole, flavonoid, indole-3-acetic acid, naringenin, quercetin, 2, 3, 5-triiodobenzoic acid

Aвstract. The effects of removal of young fruit and application of auxin transport inhibitors on endogenous indole3-acetic acid (IAA) and abscisic acid (ABA) concentrations were examined in relation to the response of mature 'Valencia' orange [Citrus sinensis (L.) Osb.] fruit to abscission materials. ABA concentrations were increased in the fruit abscission zone and pulp but not in the pedicel, peel, or seed of mature fruit by removal of young fruit during the period of reduced response of mature fruit to abscission materials in early May. However, removal of young fruit slightly decreased IAA concentrations in leaves and the abscission zone and pedicel of mature fruit but had no effect on the IAA concentrations in the peel, pulp, or seed of mature fruit. Young fruit had higher IAA concentrations in the abscission zone and pedicel than mature fruit. Application of 2,3,5-triiodobenzoic acid (TIBA), an IAA transport inhibitor, reduced IAA concentrations in the abscission zone of mature fruit but did not influence the IAA concentrations in the pedicel and peel when applied directly to an absorbent collar tied around the pedicel $2 \mathrm{~cm}$ above the fruit abscission zone during the less responsive period in early May. ABA concentrations were increased drastically in the fruit abscission zone and pedicel but not in peel by TIBA application. Applications of ABA, or IAA transport inhibitors such as naringenin, quercetin, or TIBA comparably increased the response of mature fruit to the abscission material 5-chloro-3-methyl-4-nitro-1 $H$-pyrazole (CMN-pyrazole) in early May. These data suggest that young fruit reduce the response of mature 'Valencia' oranges to abscission materials through increasing IAA concentrations and decreasing ABA concentrations in the abscission zone of mature 'Valencia' orangees.
\end{abstract}

Strong attachment of mature orange [Citrus sinensis (L.) Osb.] fruit to the tree at harvest is a major factor hampering the efficiency and economy of commercial mechanical harvesting of oranges. Without the aid of fruit loosening agents, the current mechanical harvesting systems fail to recover all of the fruit from citrus trees (Whitney and Harrell, 1989). However, it has been challenging to find a desirable abscission material to aid mechanical harvesting of the late-season cultivar Valencia, which is harvested from late March through June under Florida conditions. Unlike early and midseason orange cultivars that respond readily to abscission materials, 'Valencia' oranges have an inconsistent response to abscission materials throughout the harvest season (Hartmond et al., 2000; Wheaton et al., 1977; Yuan et al., 2001a). Mature 'Valencia' oranges have a good response to abscission materials, and fruit detachment force (FDF) is reduced markedly by effective abscission materials from mid-February through mid-April. However, the response of mature 'Valencia' oranges to abscission materials is greatly reduced in late April and early May, referred to as the less responsive period (Hartmond et al., 2000; Holm and Wilson, 1976; Yuan et al., 2001a). The factors responsible for the less responsive period are not fully understood.

Endogenous plant hormones have been implicated in the abscission of leaves, flowers, and immature and mature fruit. It has been suggested that the endogenous concentrations of indole-3-acetic acid (IAA) must fall below a certain threshold in the abscission zone to promote abscission (Goren, 1993; Osborne, 1989; Yuan et al., 2001b). The IAA flux across the abscission zone of leaves,

Received for publication 31 Oct. 2002. Accepted for publication 24 Jan. 2003. Florida Agricultural Experiment Station journal series R-08948. We gratefully acknowledge the financial support of the Florida Department of Citrus and the assistance of Ulrich Hartmond, Angela Grant and Herbert N. Nigg.

${ }^{1}$ Corresponding author; e-mail jkbu@1al.ufl.edu. flowers, and fruit appears to determine the sensitivity of those organs to ethylene and subsequent abscission (Brown, 1997). Application of synthetic IAA can also effectively reduce preharvest drop of oranges (Gardner et al., 1950; Zur and Goren, 1977). In addition, using bean leaf explants, Tucker et al. (1988) reported that auxin, when applied $4 \mathrm{~h}$ before a 48 -h treatment of ethylene, inhibited ethylene-induced expression of the cellulase gene and de novo synthesis of cellulase, an important hydrolytic enzyme involved in cell wall degradation and subsequent loosening. In contrast to IAA, high concentrations of abscisic acid (ABA) seem to be related to promotion of fruit abscission. It is well documented that endogenous ABA is positively associated with young fruit abscission in apple (Vernieri et al., 1992), cotton (Guinn and Brummett, 1988), litchi (Yuan and Huang, 1988), and citrus (Gomez-Cadenas et al., 2000; Sagee and Erner, 1991; Talon et al., 1990). Application of exogenous ABAnot only promoted young citrus fruit abscission (Okuda, 1999) but it also increased the response of mature 'Valencia' oranges to the abscission chemical cycloheximide (Cooper and Henry, 1972). ABA may promote fruit abscission through stimulating ethylene biosynthesis (Gomez-Cadenas et al., 2000; Goren, 1993).

During most of the 'Valencia' harvest season, new vegetative shoots and young fruit for the following year's crop grow concurrently (Wheaton et al., 1977; Yuan et al., 2001a). These rapidly growing tissues are rich sources of endogenous plant hormones such as IAA and gibberellins (Goldschmidt, 1976; Hofman, 1990; Plummer et al., 1991). It has been conjectured that endogenous plant hormones from these rapidly growing young tissues might be factors responsible for the less responsiveness of mature 'Valencia' oranges to abscission chemicals (Holm and Wilson, 1976; Rasmussen, 1973; Wheaton et al., 1977). Our previous results showed that the abscission zone of mature 'Valencia' oranges has high concentrations of IAA and low concentrations of ABA 
during the less responsive period (Yuan et al., 2001b). Concurrent studies showed that removal of young fruit or application of 2,3,5-triiodobenzoic acid (TIBA), an inhibitor of IAA transport, can overcome the lack of response of mature 'Valencia' oranges to abscission materials during the less responsive period (Yuan et al., 2001a, 2002). Further, naphthalene acetic acid (NAA), a synthetic IAA, effectively inhibited fruit loosening caused by the abscission material ethephon, an ethylene-releasing compound (Yuan et al., 2002).

In the present study, we monitored the seasonal variation in the response of 'Valencia' oranges to abscission chemical 5-chloro-3methyl-4-nitro-1 $H$-pyrazole (CMN-pyrazole) from early October to late June of the following year. The effect of removal of young fruit or the application of TIBA, an inhibitor of IAA transport, on endogenous concentrations of IAA and ABA in fruit and fruit abscission zone is also described. In addition, the effect of applications of ABA, or naturally occurring IAA transport inhibitors such as quercetin, a flavonoid, or the flavonoid precursor naringenin (Brown et al., 2001; Jacobs and Rubery, 1988), on the response of mature 'Valencia' oranges to abscission material CMN-pyrazole was evaluated during the less responsive period.

\section{Materials and Methods}

Plant material. All experiments were conducted with 11-yearold (2000), 12-year-old (2001), or 13-year-old (2002) 'Valencia' orange trees grafted on rough lemon(Citrus jambhiri Lush) rootstock from a previously described grove located at the Citrus Research and Education Center, Lake Alfred, Fla. (Yuan et al., 2001a).

SEASONAL VARIATION IN THE RESPONSE OF MATURE FRUIT TO CMNPYRAZOLE. Starting on 16 Oct. 2000 and ending on 6 June 2001, a group of 20 uniform fruit were selected and marked on each of eight trees on each date at 2- or 4-week intervals. A randomized complete block design with four blocks of two trees each was used. One tree of 20 marked fruit in each block was sprayed with a solution of $\mathrm{CMN}$-pyrazole at $150 \mathrm{mg} \cdot \mathrm{L}^{-1}$ containing $0.125 \%$ of the adjuvant Kinetic (Setre Chem. Co., Memphis, Tenn.) using a pressured hand sprayer. Another tree of 20 marked fruit in each block was sprayed only with $0.125 \%$ Kinetic and served as a control. Internal ethylene concentration of five fruit from each of eight trees was determined $2 \mathrm{~d}$ after application of CMN-pyrazole as described previously (Yuan et al., 2001a). Briefly, internal air was evacuated by vacuum from fruit submerged in degassed water and collected. Ethylene concentration was measured with a gas chromatograph (Hewlett-Packard, Avondale, Pa.) equipped with an activated alumina column and flame ionization detector. FDF was measured $7 \mathrm{~d}$ after treatment using a digital force gauge (Force Five, Wagner Instruments, Greenwich, Conn.). The force (in newtons) of abscised fruit was included in the calculation of mean FDF values.

EFFECTS OF REMOVAL OF YOUNG FRUIT ON ENDOGENOUS CONCENTRATIONS OF IAA AND ABA. Six mature trees were selected and grouped into three blocks of two trees each. Flowers and young fruit on one tree from each block were removed on 30 Mar. 2000. The new vegetative shoots or leaves were not removed. Another tree from each block was not manipulated and served as a control. Sixty mature fruit with pedicels 3 to $4 \mathrm{~cm}$ in length were collected from each tree on 29 Mar. (just before removal of flowers and young fruit and during the responsive period), 9 May (during the less responsive period) and 23 June of 2000 (after the less responsive period), and were immediately separated into peel, pulp, seed, pedicel, and abscission zone. Young fruit were collected from each of three control trees on 9 May and 23 June. The young fruit collected on 9 May were separated only into fruit, abscission zone, and pedicel due to small fruit size. The young fruit collected on 23 June, however, were separated into peel, pulp, seed, pedicel, and abscission zone. Seventy-five mature leaves from spring vegetative shoots were collected from each tree. The fruit abscission zones were removed according to the method of Kazokas and Burns (1998). Promptly after the separation of fruit, all samples were frozen in liquid nitrogen, lyophilized, and used for measurement of free IAA and ABA.

EFFECTS OF TIBA ON ENDOGENOUS CONCENTRATIONS OF IAA AND ABA IN 2000. Six mature trees were selected and grouped into three blocks of two trees each. Three hundred mature fruit were selected and marked on each of six trees. One tree of 300 marked fruit in each block was treated with TIBA (from Sigma-Aldrich Chem., St Louis, Mo.) at $5 \mathrm{~mm}$ containing $0.1 \%$ Tween 20 adjuvant by saturating an absorbent twisted tissue paper collar tied around the pedicel, $\approx 2 \mathrm{~cm}$ above the fruit abscission zone on 19 June 2000. The other tree of 300 marked fruit in each block was treated with only $0.1 \%$ Tween 20 and served as a control. TIBA was dissolved in pure ethanol and the final ethanol concentration was $0.5 \%(\mathrm{v} / \mathrm{v})$ in TIBA and control solutions. Seventy-five fruit with pedicels or stems 5 to $6 \mathrm{~cm}$ in length were collected from each tree at 0,1 , 3 , and $7 \mathrm{~d}$ after treatment application, and immediately separated into fruit abscission zone, pedicel 1 (the section of pedicel above the absorbent twisted tissue paper collar), and pedicel 2 (the section of pedicel below the absorbent twisted tissue paper collar). Promptly after the separation of fruit, all samples were frozen in liquid nitrogen, lyophilized, and used for measurement of free IAA and ABA.

EFFECTS OF TIBA ON ENDOGENOUS CONCENTRATIONS OF IAA AND ABA IN 2001. Six mature trees were selected and grouped into three blocks of two trees each. One hundred mature fruit were selected and marked on each of six trees. TIBA at $5 \mathrm{mM}$ containing $0.1 \%$ Tween 20 adjuvant was applied to one tree of 100 marked fruit in each block by saturating an absorbent twisted tissue paper collar tied around the pedicel, $\approx 2 \mathrm{~cm}$ above the fruit abscission zone, every 2 or $3 \mathrm{~d}$ from $20 \mathrm{Apr}$. (just before the beginning of the less responsive period) to 6 May 2001. At the same time, the other tree of 100 marked fruit in each block was treated with only $0.1 \%$ Tween 20 and served as a control. One hundred fruit with pedicels or stems 5 to $6 \mathrm{~cm}$ in length were collected from each tree on 7 May 2001 (during the less responsive period), and immediately separated into fruit abscission zone, pedicel 1 ( the section of pedicel above the absorbent twisted tissue paper collar), and pedicel 2 (the section of pedicel below the absorbent twisted tissue paper collar). Promptly after the separation of fruit, all samples were frozen in liquid nitrogen, lyophilized, and used for measurement of free IAA and ABA.

EXTRACTION, PURIFICATION, AND MEASUREMENT OF FREE IAAAND ABA. Details of the extraction, purification and measurement of free IAA and ABA of the samples have been described previously (Yuan et al., 2001b). In brief, plant materials were extracted three times with $80 \%$ methanol containing butylated hydroxytoluene (BHT) and purified with a column system consisting of an insoluble polyvinyl pyrrolidone (PVP), a dieethylaminoethyl(DEAE) Sephadex anion exchange column, and a Sep-Pak $\mathrm{C}_{18}$ cartridge (Waters, Milford, Mass.). The samples were further purified and fractioned by $\mathrm{C}_{18}$-reverse-phase high performance liquid chromatography (HPLC). The fractions containing IAA were methylated with diazomethane before assaying by an enzyme linked immunosorbent assay (ELISA). IAA and ABA were quantified by ELISA using 


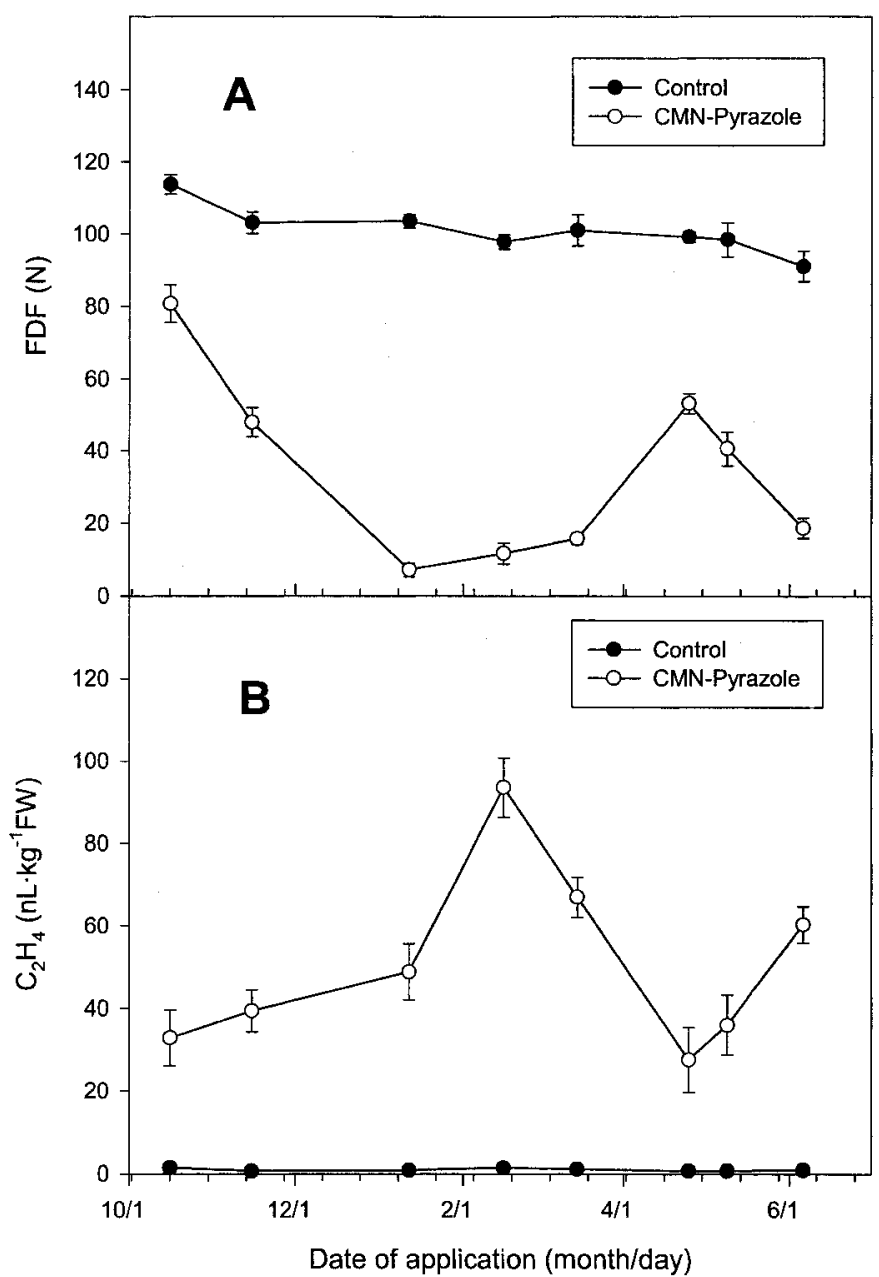

Fig. 1. Seasonal variation in fruit detachment force (FDF) (A) and fruit ethylene production $(\mathbf{B})$ in response to CMN-pyrazole at $150 \mathrm{mg} \cdot \mathrm{L}^{-1}$ in 'Valencia' oranges in the 2000-01 season. FDF was measured $7 \mathrm{~d}$ after treatment. Data are means $\pm \operatorname{SE}(\mathrm{n}=60$ in $\mathbf{A}$ and 20 in $\mathbf{B}$, respectively). monoclonal antibodies against IAA and ABA (Agdia Inc., Elkhart, Ind.). The data presented are the means of triplicate analyses of three independent replicates. One hundred microliters of ${ }^{3} \mathrm{H}-\mathrm{IAA}$ $(0.67 \mathrm{~Bq})$ and ${ }^{14} \mathrm{C}-\mathrm{ABA}(0.83 \mathrm{~Bq})$ were added as internal standards to the plant samples to determine the recovery rate. The recovery was $\approx 70 \%$ for IAA and $52 \%$ for ABA, respectively.

EFFECTS OF QUERCETIN, NARINGENIN, TIBA, AND ABA ON FRUIT ABSCISSION RESPONSE OF MATURE FRUIT TO CMN-PYRAZOLE. A group of 10 uniform fruit were selected and marked on each of 30 trees on 23 Apr. 2002. A randomized complete-block design with three blocks of 10 trees each was used. CMN-pyrazole at 0 or $200 \mathrm{mg} \cdot \mathrm{L}^{-1}$ and naringenin at $5 \mathrm{~mm}$, quercetin at $5 \mathrm{~mm}$, TIBA at $5 \mathrm{~mm}$, or $\mathrm{ABA}$ at $0.95 \mathrm{~mm}$ were applied in combination to one tree of 10 marked fruit in each block. TIBA, ABA, or naringenin (all from Sigma-Aldrich) were dissolved in pure ethanol and the final ethanol concentration was below $0.5 \%(\mathrm{v} / \mathrm{v})$. Quercetin (from Sigma-Aldrich) was dissolved in aqueous solutions with a $\mathrm{pH}$ value of 8 adjusted with $0.5 \mathrm{~N} \mathrm{NaOH}$. Naringenin, quercetin, or TIBA solutions containing $0.1 \%$ Tween 20 adjuvant were applied by saturating an absorbent twisted tissue paper collar tied around the pedicel, $\approx 2 \mathrm{~cm}$ above the fruit abscission zone, every 3 or $4 \mathrm{~d}$ from $23 \mathrm{Apr}$. (approximately before the beginning of the less responsive period) to 6 May 2002. ABA solutions containing $0.1 \%$ Tween 20 were applied by saturating an absorbent twisted tissue paper collar tied around the fruit abscission zone, every 3 or $4 \mathrm{~d}$ from 23 Apr. to 6 May 2002. CMN-pyrazole containing $0.1 \%$ Tween 20 was applied on 7 May 2002 during the less responsive period by dipping the entire fruit, including the abscission zone, into the treatment solution. The control solutions had equivalent ethanol and $\mathrm{pH}$ value as the treatment solutions. The absorbent twisted tissue paper collars tied around the pedicel or the fruit abscission zone were removed just before CMN-pyrazole treatment. FDF was measured $7 \mathrm{~d}$ after treatment as described above.

\section{Results}

Seasonal Variation in the Response of mature fruit to CMN-PYRAzOLE. The response of 'Valencia' oranges to CMN-

Table 1. Effects of removal of young fruit on endogenous ABA concentrations (pmol. $\mathrm{g}^{-1}$ dry weight) in mature fruit tissues, leaves, and young fruit tissues of 'Valencia' oranges in 2000. Values presented are means $\pm \operatorname{SE}(n=3)$.

\begin{tabular}{|c|c|c|c|c|c|c|}
\hline \multirow[b]{3}{*}{$\begin{array}{l}\text { Plant } \\
\text { tissues }\end{array}$} & \multicolumn{6}{|c|}{ Sampling date } \\
\hline & \multicolumn{2}{|c|}{29 March } & \multicolumn{2}{|c|}{9 May } & \multicolumn{2}{|c|}{23 June } \\
\hline & Control & $\begin{array}{l}\text { Removal of } \\
\text { young fruit }\end{array}$ & Control & $\begin{array}{l}\text { Removal of } \\
\text { young fruit }\end{array}$ & Control & $\begin{array}{l}\text { Removal of } \\
\text { young fruit }\end{array}$ \\
\hline $\mathrm{AZ} \mathrm{y}^{\mathrm{y}}$ & $763.57 \pm 50.30$ & $780.27 \pm 60.1$ & $512.26 \pm 57.34$ & $1552.44 \pm 184.34$ & $1621.50 \pm 125.90$ & $1459.75 \pm 240.98$ \\
\hline Pedicel & - & - & $67.29 \pm 4.89$ & $85.75 \pm 24.96$ & $49.22 \pm 6.52$ & $34.76 \pm 2.31$ \\
\hline Peel & $542.79 \pm 38.51$ & $549.31 \pm 41.32$ & $475.18 \pm 13.58$ & $542.49 \pm 16.36$ & $218.06 \pm 31.38$ & $231.28 \pm 17.94$ \\
\hline Seed & $473.84 \pm 60.00$ & $470.32 \pm 32.51$ & $828.32 \pm 150.0$ & $777.49 \pm 162.38$ & $1023.0 \pm 160.21$ & $1060.0 \pm 131.03$ \\
\hline Leaves & --- & --- & $287.33 \pm 4.86$ & $288.82 \pm 45.90$ & --- & --- \\
\hline \multicolumn{7}{|l|}{ Young fruit } \\
\hline Whole fruit & --- & --- & $313.60 \pm 12.23$ & --- & --- & --- \\
\hline $\mathrm{AZy}$ & --- & --- & $405.27 \pm 11.34$ & --- & $190.02 \pm 11.60$ & --- \\
\hline Pedicel & --- & --- & $457.42 \pm 10.20$ & --- & $164.59 \pm 15.33$ & --- \\
\hline
\end{tabular}

${ }^{2}$ Full bloom was late Mar. 2000 for young fruit. Young fruit or flowers were removed on 30 Mar. 2000.

y Abscission zone. 
Table 2. Effects of removal of young fruit on endogenous IAA concentrations ( $\mathrm{pmol} \cdot \mathrm{g}^{-1} \mathrm{dry}$ weight) in mature fruit tissues, leaves, and young fruit tissues of 'Valencia' oranges in 2000. Values presented are means $\pm \operatorname{SE}(n=3)$.

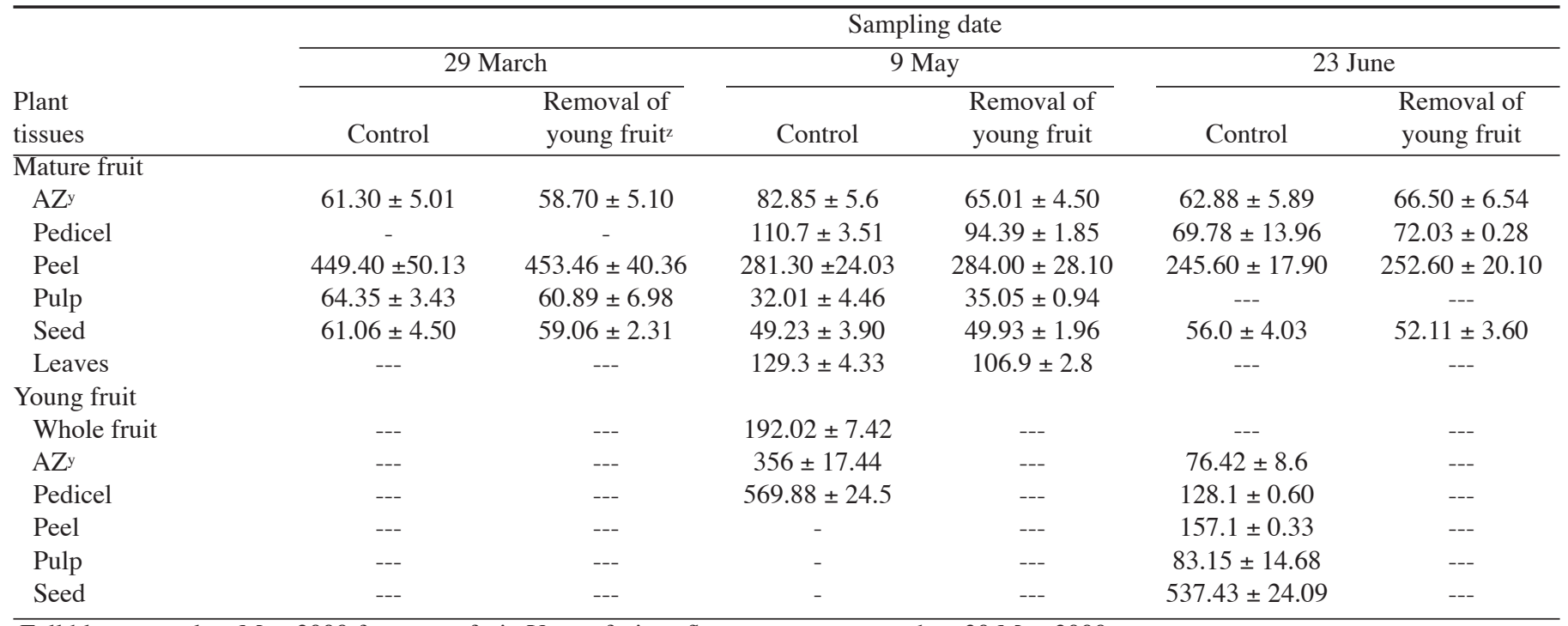

zFull bloom was late Mar. 2000 for young fruit. Young fruit or flowers were removed on 30 Mar. 2000.

yAbscission zone.

pyrazole, as indicated by FDF and fruit ethylene production, was inconsistent from mid-October to early June of the following year (Fig. 1A and B). There were two distinguishable periods during which fruit had less response to $\mathrm{CMN}$-pyrazole over the 8-month observation period. The first one occurred in a period during mid-October and November, and the second one from late April to early May of the following year. CMN-pyrazole at $150 \mathrm{mg} \cdot \mathrm{L}^{-1}$ caused $<50 \%$ reduction in FDF during the two less responsive periods compared to more than $80 \%$ reduction in FDF during the responsive period from late January to mid-April or after late May. CMN-pyrazole also induced less fruit ethylene production during the two less responsive periods than during the responsive period.

EFFECTS OF REMOVAL OF YOUNG FRUIT ON ENDOGENOUS CONCENTRATIONS OF IAA AND ABA. In general, there was no difference in ABAconcentrations in the pedicel, abscission zone, peel, pulp, and seed of mature 'Valencia' oranges between young fruit-removed trees and control trees on 29 Mar., 9 May, or 23 June (Table 1). However, during the less responsive period on 9 May, ABAconcentrations in the fruit abscission zone and pulp of mature 'Valencia' oranges from young fruit-removed trees were 3-fold and 9-fold higher than from control trees, respectively. ABA concentrations in leaves were not affected by removal of young fruit. Young fruit from control trees had lower ABA concentrations in abscission zone, peel, and pulp but higher ABA concentrations in pedicel and seed when compared to mature fruit. No young fruit were found on manipulated trees due to removal of young fruit.

IAA concentrations in the abscission zone and pedicel of mature 'Valencia' oranges were slightly decreased by removal of young fruit during the less responsive period on 9 May but not during the responsive period on 29 Mar. or 23 June (Table 2). However, removal of young fruit had no significant influence on IAA concentrations in peel, pulp, and seed of mature 'Valencia' oranges on any sampling date. Leaves from young fruit-removed trees had lower IAA concentrations than those from control trees. During the less responsive period on 9 May, IAA concentrations in the abscission zone and pedicel of young fruit were 4-fold and 5-fold higher than those in the counterparts of mature fruit, respectively. In the young fruit, seed had the highest IAA con-

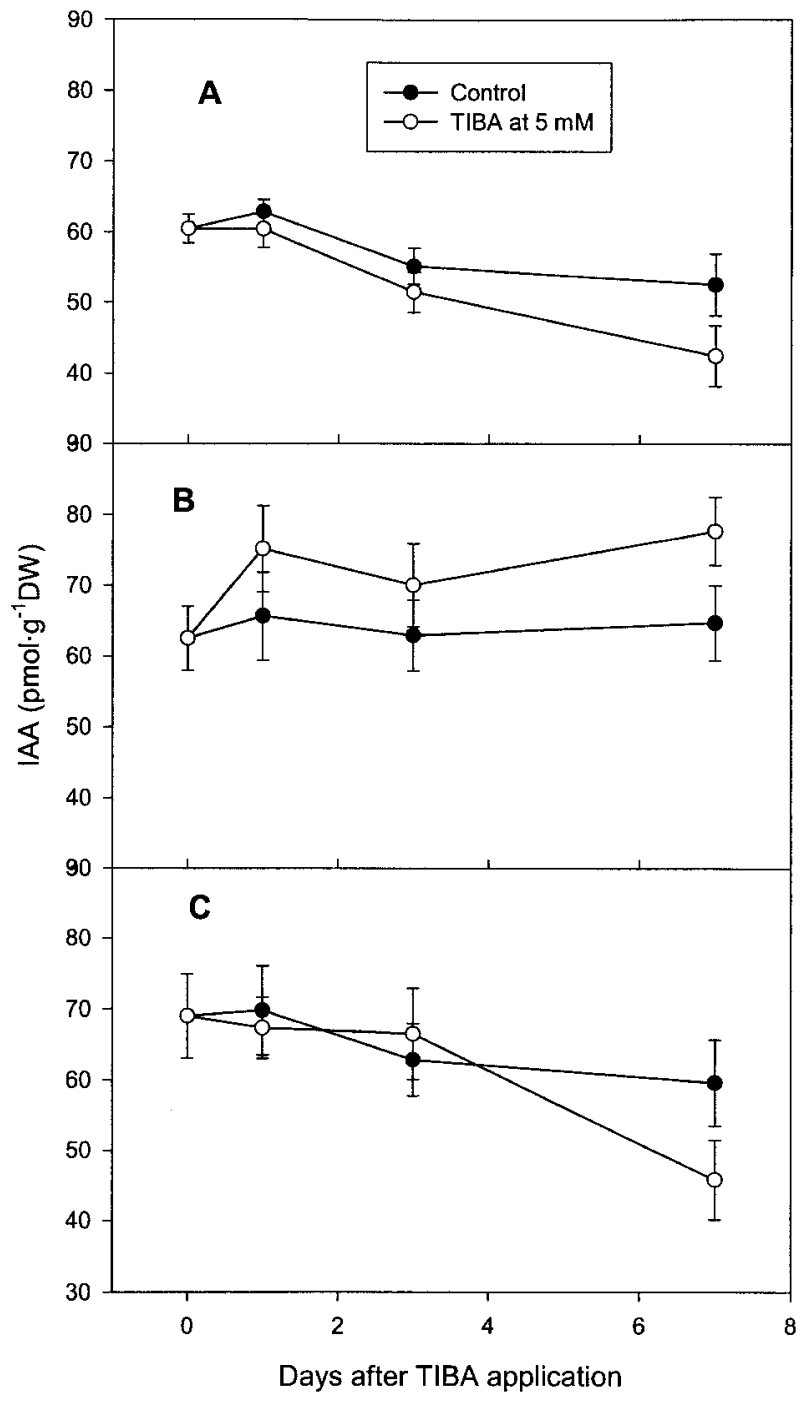

Fig. 2. Effect of a single TIBA application on endogenous IAA concentrations in the $(\mathbf{A})$ abscission zone, $(\mathbf{B})$ pedicel 1 , and $(\mathbf{C})$ pedicel 2 of mature 'Valencia' oranges in 2000 season. Data are means $\pm \operatorname{SE}(n=3)$. 


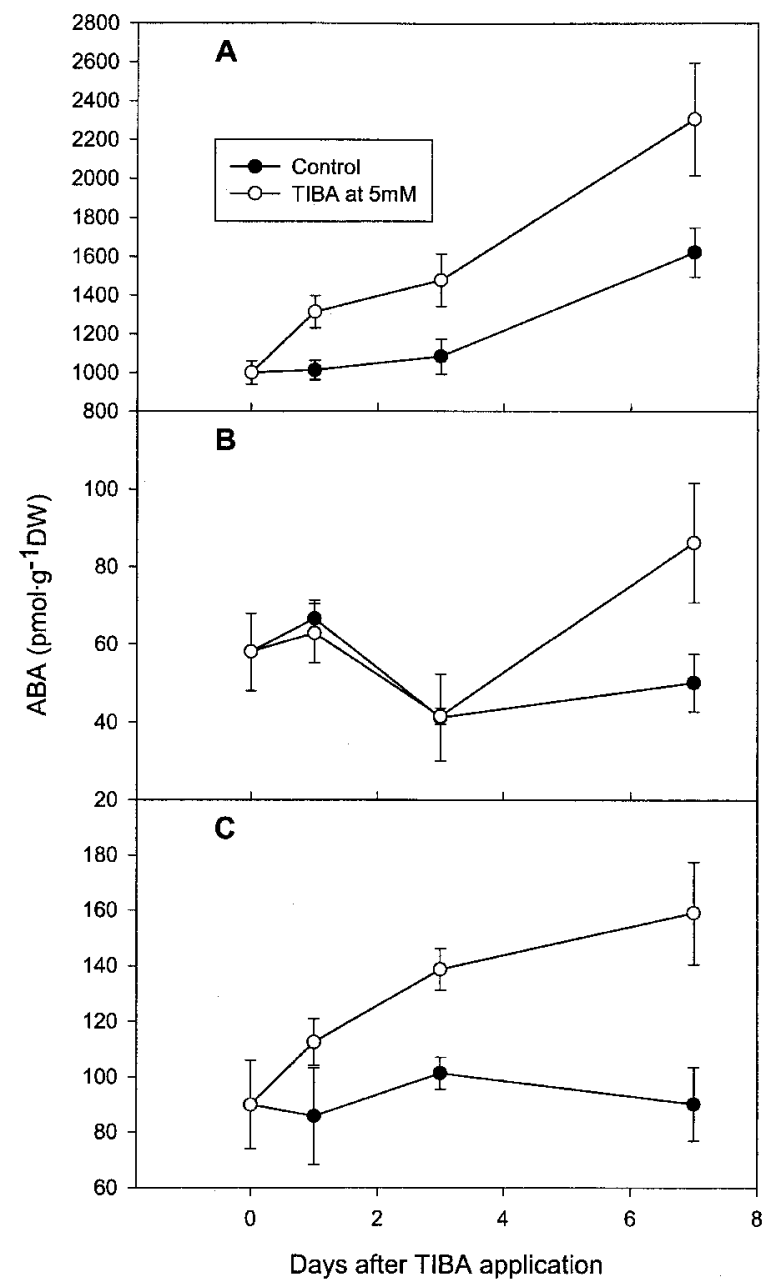

Fig. 3. Effect of a single TIBA application on endogenous abscisic acid concentrations in the (A) abscission zone, $(\mathbf{B})$ pedicel 1, and $(\mathbf{C})$ pedicel 2 of mature 'Valencia' oranges in 2000 season. Data are means $\pm \mathrm{SE}(\mathrm{n}=3)$. in IAA concentrations in pedicel 1 , pedicel 2 , or peel between TIBA application and control (Fig. 4). ABA concentrations in the abscission zone of TIBA treated fruit were about two and one-half times higher than of untreated control fruit. TIBA application also increased ABA concentrations in pedicel 1 and 2 but had no influence on $\mathrm{ABA}$ concentrations in peel (Fig. 5).

EFFECTS OF QUERCETIN, NARINGENIN, TIBA, AND ABA ON FRUIT ABSCISSION RESPONSE OF MATURE FRUIT TO CMN-PYRAZOLE. Without application of CMN-pyrazole, only TIBA application decreased FDF by $\approx 11 \%$ (Table 3). CMN-pyrazole alone decreased FDF from $\approx 96$ to $\approx 63$ newtons during the less responsive period. The combination of CMN-pyrazole with ABA, TIBA, naringenin, or quercetin further reduced the FDF.

\section{Discussion}

In oranges, it has been suggested that abscission materials effectively reduce FDF and enhance fruit abscission by stimulating ethylene production directly or indirectly, followed by initiation of cellulase and polygalacturonase gene expression, de novo synthesis of hydrolytic enzymes in the fruit abscission zone, degradation of cell wall polymers, and finally organ separation (Goren, 1993; Holm and Wilson, 1976; Kazokas and Burns, 1998). The response of fruit to abscission materials is influenced by internal and external factors as well. Our results are in agreement with previous reports that a period of less responsiveness of mature 'Valencia' oranges to abscission materials exists in late April and early May during the harvest season (Hartmond et al., 2000; Wheaton et al., 1977; Yuan et al., 2001a). In addition, 'Valencia' oranges also had a poor response to CMN-pyrazole before mid-November, indicating that the stage of fruit development appears to influence the sensitivity and thereby response of fruit to the abscission material CMN-pyrazole. Similarly, Cooper and Henry (1972) found that 'Valencia' oranges also had a poor response to the abscission material cycloheximide both before December and in early May of the following year.

Our previous results showed that rapidly growing young fruit were the major factors responsible for the occurrence of the less centrations followed by the peel, pedicel, pulp and abscission zone on 23 June.

EFFECTS OF TIBAON ENDOGENOUS CONCENTRATIONS OF IAA AND ABA. In 2000, a single TIBA application had no effect on IAA concentrations in fruit abscission zone, pedicel 1 and 2 until $7 \mathrm{~d}$ after treatment (Fig. 2). IAA concentrations were reduced in fruit abscission zone and pedicel 2 , but increased in pedicel 1 by a single TIBA application $7 \mathrm{~d}$ after treatment. A single TIBA application drastically enhanced $\mathrm{ABA}$ concentrations in fruit abscission zone and pedicel 2 one day after treatment (Fig. 3). ABA concentrations in the pedicel 1 were not affected by a single TIBA application 1 or $3 \mathrm{~d}$ after treatment but increased $7 \mathrm{~d}$ after treatment.

In 2001, TIBA applications were made to the stem six times over a 17-d period during the less responsive period. TIBA-treated fruit had slightly lower IAA concentrations in fruit abscission zone than untreated fruit but there was no difference

Fig. 4. Effect of repeated TIBA application on endogenous IAA concentrations in the abscission zone, pedicel 1, pedicel

2, and peel of mature 'Valencia' oranges in 2001 season. Data are means $\pm \operatorname{SE}(\mathrm{n}=3)$.

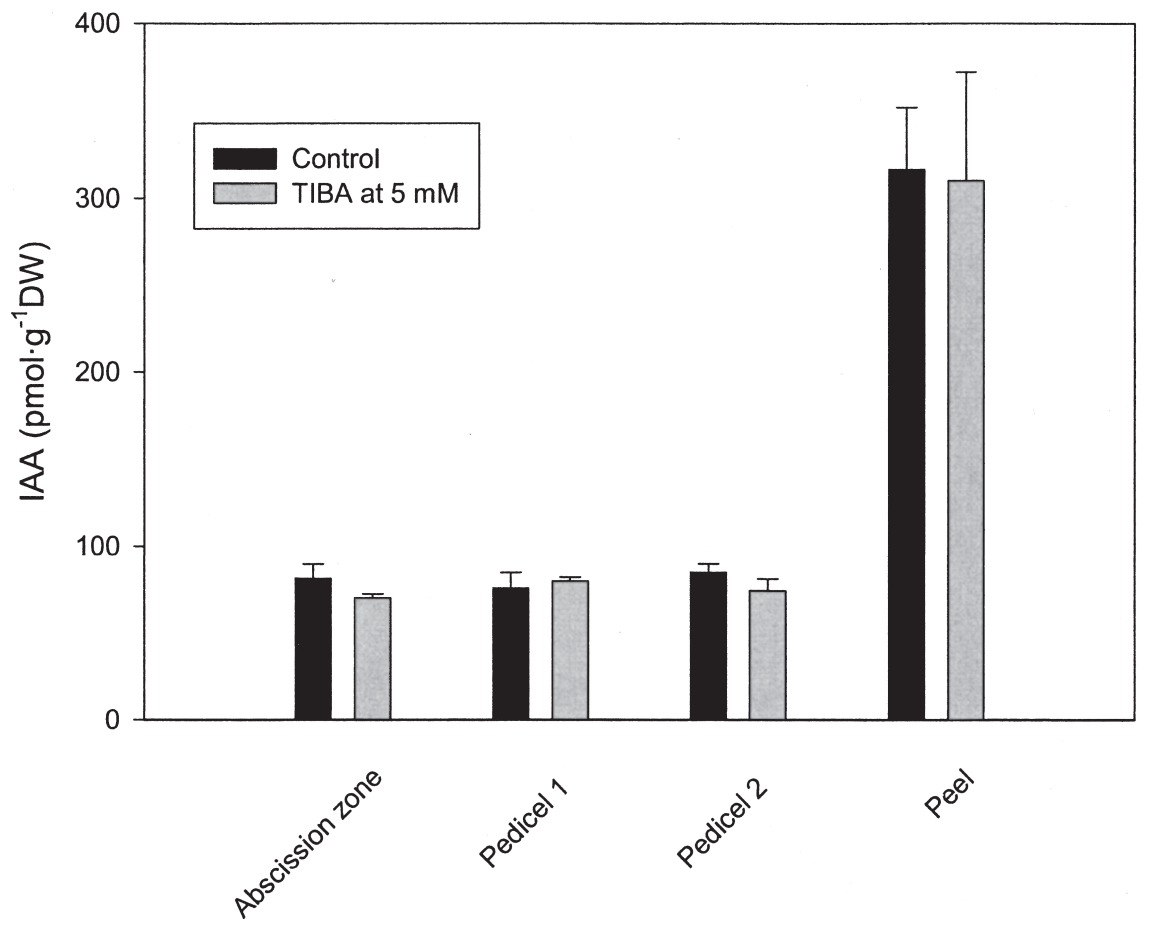




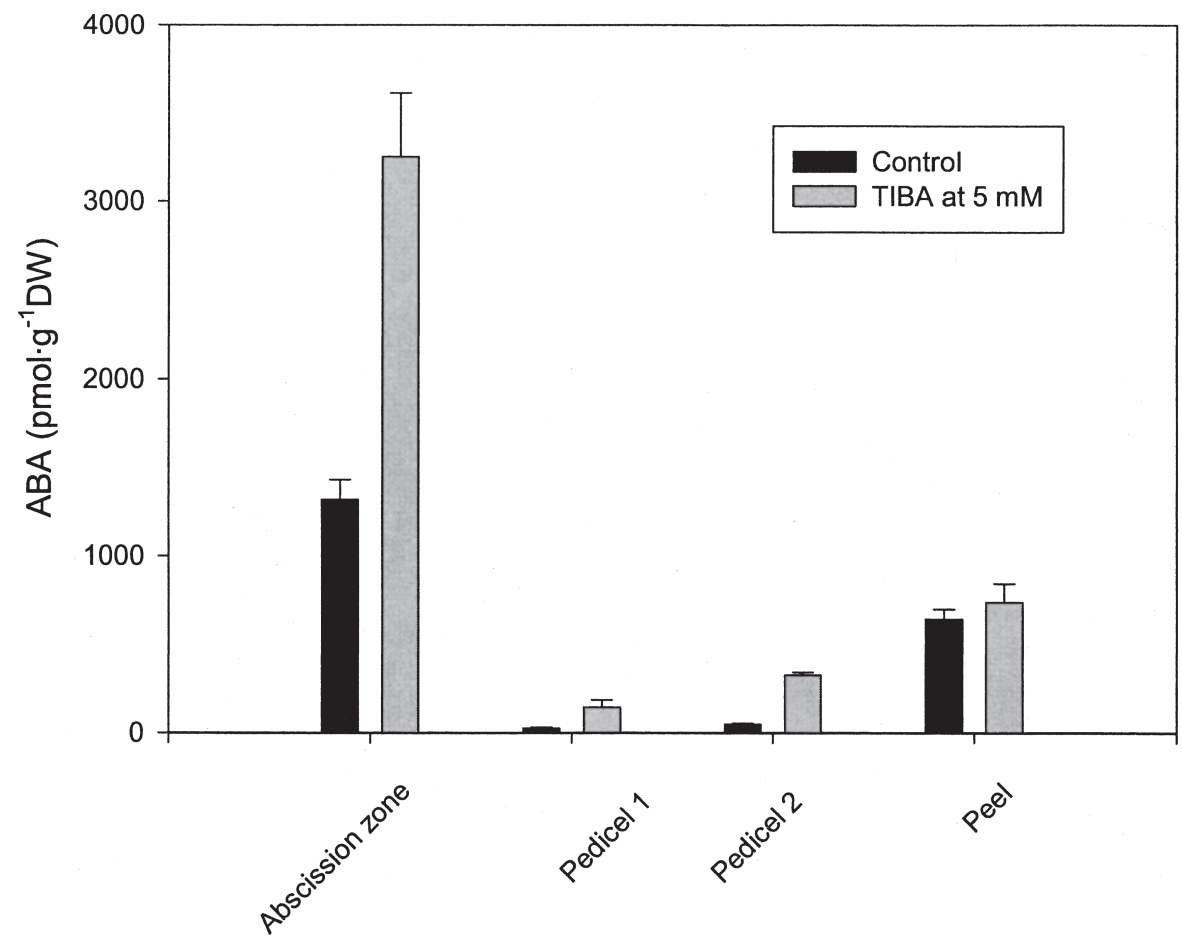

the levels of endogenous IAA in the abscission zone leads to increased sensitivity of the abscission zone to ethylene (Huberman et al., 1997; Osborne, 1989). Application of NAA, a synthetic auxin, to the abscission zone of mature 'Valencia' oranges $24 \mathrm{~h}$ before application of ethephon effectively inhibited fruit loosening induced by ethephon (Yuan et al., 2002). On the other hand, ABA seems to be positively associated with fruit abscission. ABA can promote the production of ACC, the precursor of ethylene, thereby promoting young citrus fruit abscission (Gomez-Cadenas et al., 2000; Okuda, 1999). In our study, exogenous ABA increased mature 'Valencia' oranges loosening induced by $\mathrm{CMN}$-pyrazole during the less responsive period when applied directly to the fruit abscission zone (Table 3). Similarly, repeated sprays of ABA to mature 'Valencia' oranges also considerably increased fruit ethylene production and fruit loosening caused by the application of abscission material cycloheximide during the less responsive period on May 1 (Cooper and Henry, 1972). Therefore, it is likely that young fruit reduce the sensitivity and thereby the response of

Fig. 5. Effect of repeated TIBA application on endogenous ABA concentrations in the abscission zone, pedicel 1, pedicel 2, and peel of mature 'Valencia' oranges in 2001 season. Data are means $\pm \operatorname{SE}(n=3)$.

responsive period, and removal of young fruit could overcome the lack of response of mature 'Valencia' oranges to abscission materials during the less responsive period in early May (Yuan et al., 2001a). In the present study, as a result of removal of young fruit, IAA concentrations in leaves and the abscission zone of mature 'Valencia' oranges decreased whereas ABAconcentrations in the abscission zone of mature 'Valencia' oranges increased drastically during the less responsive period in early May. In addition, young 'Valencia' oranges had much higher IAA concentrations in the pedicel, abscission zone, and especially seed, than mature fruit. These results combined with our previous findings that the abscission zone of mature fruit had high IAA but low ABA concentrations during the less responsive period (Yuan et al., 2001b), suggest that the movement of IAA from young fruit to mature fruit and leaves most likely occurs. However, little is known about the sources of ABA. Some signals from young fruit may indirectly affect the biosynthesis of ABA. It has been suggested that the balance between plant growth promoters and inhibitors controls fruit abscission (Addicott, 1982; Brown, 1997; Goren, 1993). IAA plays an important role in the control of leaf and fruit abscission (Goren, 1993; Osborne, 1989). Reduction in mature fruit to abscission materials through directly increasing IAA concentrations and indirectly reducing ABA concentrations in the abscission zone of mature fruit in 'Valencia' orange trees in late April and early May.

Using ${ }^{13} \mathrm{C}_{6}$-IAA, Okuda and Hirabayashi (1998) found that TIBA was an effective synthetic IAA transport inhibitor in citrus. In the present study, our results demonstrated that TIBA application reduced IAA concentrations but increased ABAconcentrations in mature fruit abscission zones when applied to the pedicel about $2 \mathrm{~cm}$ above the mature fruit abscission zone. The decreased ratio of IAA to ABA may partly result from blockage of the movement of IAA from young fruit to the abscission zone of mature fruit by TIBA application. As a result, the lack of the response of mature 'Valencia' oranges to abscission materials in late April and early May was overcome (Yuan et al., 2002). Many reports have confirmed that flavonoids including quercetin and naringenin are endogenous inhibitors of IAA transport in plants (Brown et al., 2001; Jacobs and Rubery, 1988). Similar to TIBA application, application of quercetin and naringenin also comparably promoted fruit loosening caused by CMN-pyrazole application during the less responsive period in early May. These results provide further evidence to support the above suggestion that young fruit reduce the sensitivity of mature 'Valencia' oranges to abscission materials and thereby the response of mature fruit to abscission materials through directly increasing

Table 3. Effects of CMN-Pyrazole alone or in combination with ABA, TIBA, naringenin, or quercetin on fruit detachment force (FDF) (newton) of mature 'Valencia' oranges. ${ }^{\mathrm{C}}$

\begin{tabular}{|c|c|c|c|c|c|}
\hline \multirow[b]{2}{*}{$\begin{array}{l}\text { CMN-pyrazole } \\
(\mathrm{ppm})\end{array}$} & \multicolumn{5}{|c|}{ Other chemicals } \\
\hline & Water & $\begin{array}{c}\text { ABA } \\
(0.95 \mathrm{~mm})\end{array}$ & $\begin{array}{c}\text { TIBA } \\
(5 \mathrm{~mm})\end{array}$ & $\begin{array}{l}\text { Naringenin } \\
(5 \mathrm{~mm})\end{array}$ & $\begin{array}{l}\text { Quercetin } \\
\text { (5 mM) }\end{array}$ \\
\hline & \multicolumn{5}{|c|}{ Fruit detachment force $(\mathrm{N})$} \\
\hline 200 & $63.27 \mathrm{a}$ & $42.24 \mathrm{~b}$ & $46.41 \mathrm{~b}$ & $38.99 \mathrm{~b}$ & $36.87 \mathrm{~b}$ \\
\hline
\end{tabular}

${ }^{\mathrm{z}}$ Mean of 30 observations.

yMean separation within rows by Duncan's multiple range test, $P<0.05$. 
IAA concentrations and indirectly reducing ABA concentrations in the abscission zone of mature fruit.

The 'Valencia' fruit abscission zone has a high ratio of IAA to ABA before November (Yuan et al., 2002). Therefore, the poor response of 'Valencia' oranges to the abscission material CMNpyrazole reported herein or cycloheximide reported by Cooper and Henry (1972) in October and November might be also related to the high ratio of IAA to ABA in the fruit abscission zone. These hormones may come from fruit themselves, since the fruit are not mature and no other vigorous growing tissues, which are usually rich sources of hormones, occur simultaneously on the tree at that time.

In summary, our results provide further evidence to support our previous hypothesis that the balance between IAA and ABA in fruit abscission zone may be an important factor in determining sensitivity of mature 'Valencia' oranges to abscission materials, thereby controlling the response of mature fruit to abscission materials. Increased IAA concentrations and simultaneously decreased ABA concentrations in the abscission zone of mature 'Valencia' oranges by the presence of young fruit may account for the less responsive period in late April and early May.

\section{Literature Cited}

Addicott, F.T. 1982. Abscission. Univ California Press, Berkeley, Calif.

Brown D.E., A.M. Rashotte, A.S. Murphy, J. Normanly, B.W. Tague, W.A. Peer, L. Taiz, and G.K. Muday. 2001. Flavonoids act as negative regulators of auxin transport in vivo in Arabidopsis. Plant Physiol. 126:524-535.

Brown K.M. 1997. Ethylene and abscission. Physiol. Plant. 100: 567-576.

Cooper W.C. and W.H. Henry. 1972. Effect of growth regulators on the response of citrus fruit to cycloheximide-induced abscission. Proc. Fla. State Hort. Soc. 85:29-32.

Gardner F.E., P.C. Reece, and G.E. Horanic. 1950. The effect of 2,4-D on preharvest drop of citrus under Florida conditions. Proc. Fla. State Hort. Soc. 63:7-11.

Goldschmidt E.E. 1976. Endogenous growth substances of citrus tissue. HortScience 11:95-99.

Gomez-Cadenas A., J. Mehouachi, F.R. Tadeo, E. Primo-Millo, and M. Talon. 2000. Hormonal regulation of fruitlet abscission induced by carbohydrate shortage in citrus. Planta 210: 636-643.

Goren R. 1993. Anatomical, physiological, and hormonal aspects of abscission in citrus. Hort. Rev. 15:145-182.

Guinn G. and D.L. Brummett. 1988. Changes in free and conjugated indole-3-acetic acid and abscisic acid in young cotton fruits and their abscission zones in relation to fruit retention during and after moisture stress. Plant Physiol. 86:28-31.

Hartmond U., J.D. Whitney, J.K. Burns, and W.J. Kender. 2000. Seasonal variation in the response of 'Valencia' orange to two abscission compounds. HortScience 35:226-229.

Hofman P.J. 1990. Abscisic acid and gibberellins in the fruitlets and leaves of 'Valencia' orange in relation to fruit growth and retention. Scientia Hort. 42:257-267.

Holm R.E. and W.C. Wilson. 1976. Loss in the capacity of 'Valencia' oranges treated with abscission chemicals to produce ethylene and fruit loosening during the regreening period. Proc. Fla. State Hort. Soc. 89:35-38.

Huberman M., J. Riov, B. Aloni, and R. Goren. 1997. Role of ethylene biosynthesis and auxin content and transport in high temperatureinduced abscission of pepper reproductive organs. J. Plant Growth Regul. 16:129-135.

Jacobs M. and P. Rubery. 1988. Naturally occurring auxin transport regulators. Science 241:346-349.

Kazokas W.C. and J.K. Burns. 1998. Cellulase activity and gene expression in citrus fruit abscission zones during and after ethylene treatment. J. Amer. Soc. Hort. Sci. 123:781-786.

Okuda H. 1999. An increase in citrus fruit (Kiyomi tangor) abscission induced by $\mathrm{ABA}$ is accompanied by an increase in the abscission zone and ethylene production. J. Hort. Sci. Biotechnol. 74:422-425.

Okuda H. and T. Hirabayashi. 1998. Effect of IAA gradient between the peduncle and branch on physiological drop of citrus fruit (Kiyomi tangor). J. Hort. Sci. Biotechnol. 73:618-621.

Osborne D.J. 1989. Abscission. Critical Rev. Plant Sci. 8:103-129.

Plummer J.A., M.G. Mullins, and J.H. Vine. 1991. Seasonal changes in endogenous ABA and IAA and the influence of applied ABA and auxin in relation to shoot growth and abscission in Valencia orange (Citrus sinensis (L.) Osbeck). Plant Growth. Regul. 10:139-151.

Rasmussen G.K. 1973. The effect of growth regulators on degreening and regreening of citrus fruit. Acta Hort. 34:473-478.

Sagee O. and Y. Erner. 1991. Gibberellin and abscisic acid contents during flowering and fruit set of Shamouti orange. Scientia Hort. 53:99-107.

Talon M., L. Zacarias, and E. Primo-Millo. 1990. Hormonal changes associated with fruit set and development in mandarins differing in their parthenocarpic ability. Physiol. Plant. 79:400-406.

Tucker M.L., R. Sexton, E. del Campillo, and L.N. Lewis. 1988. Bean abscission cellulase. Plant Physiol. 88:1257-1262.

Vernieri P., A.M. Tagliasacchi, L. Forino, A. Lanfranchi, R. Lorenzi, and S. Avanzi. 1992. Abscisic acid levels and cell structure in single seed tissues of shedding affected fruits of Malus domestica Borkh. J. Plant Physiol. 140:699-706.

Wheaton T.A., W.C. Wilson, and R.E. Holm. 1977. Abscission response and color changes of 'Valencia' oranges. J. Amer. Soc. Hort. Sci. 102: 580-583.

Whitney J.D. and R.C. Harrell. 1989. Status of citrus harvesting in Florida. J. Agr. Eng. Res. 42:285-299.

Yuan R., U. Hartmond, and W.J. Kender. 2001a Physiological factors affecting response of mature 'Valencia' oranges to CMN-pyrazole. I. Effects of young fruit, shoot, and root growth. J. Amer. Soc. Hort. Sci. 126:414-419.

Yuan R., U. Hartmond, and W.J. Kender. 2001b. Physiological factors affecting response of mature 'Valencia' oranges to CMN-pyrazole. II. Endogenous concentrations of indole-3-acetic acid, abscisic acid, and ethylene. J. Amer. Soc. Hort. Sci. 126:420-426.

Yuan R., U. Hartmond, and W.J. Kender. 2002. Naphthalene acetic acid and 2,3,5-triiodobenzoic acid affect the response of mature orange fruit to abscission chemicals. HortScience 37:348-352.

Yuan R. and H. Huang. 1988. Litchi fruit abscission: its patterns, effect of shading and relation to endogenous abscisic acid. Scientia Hort. 36:281-292.

Zur A. and R. Goren. 1977. Reducing preharvest drop of 'Temple' orange fruits by 2,4-D. Role of cellulase in the calyx abscission zone. Scientia Hort. 7:237-248. 